\title{
AFLATOXIN CONTAMINATION AND MOISTURE LEVELS IN SRI LANKAN MARKET RICE
}

\author{
CHANDRA BRECKENRIDGE, U. SAMARAJEEWA AND
}

S. N. ARSECULERATNE

University of Peradeniya, Peradeniya, Sri Lanka.

(Date of receipt : 27.05.86)

(Date of acceptance : 30.09.86)

\begin{abstract}
Samples of raw and parboiled, milled rice collected from wet (Veyangoda), intermediate (Kurunegala) and dry (Anuradhapura) zones of Sri Lanka during the dry and rainy seasons of the year were analysed for the presence of moisture and aflatoxin B1. Rice contained a mean moisture content of $14.9 \pm 1.4 \%$. Although slightly higher average moisture levels were observed during the rainy season and in the wet zone, the differences in the moisture levels between the two seasons and among the three locations were not statistically significant. Of the 597 samples of rice tested, aflatoxin B1 was not detected in 525 samples (minimum detectable level $12 \mu \mathrm{g} / \mathrm{kg}$ ). Aflatoxin B1 was present at $30 \mu \mathrm{g} / \mathrm{kg}$ level in 12 parboiled samples and 60 samples contained $12-30 \mu \mathrm{g} / \mathrm{kg}$. Of the 60 samples 57 were parboiled rice. At present, rice does not appear to pose a danger through aflatoxin contamination as it is stored only for about a week at moisture levels around $15 \%$. However, with self sufficiency in rice resulting in longer durations of storage, the parboiled rice could indicate a potential danger, if efficient drying methods are not practised.
\end{abstract}

\section{Introduction}

Ariatoxins are the most potent naturally occurring hepatocarcinogens in experimental animals. ${ }^{6}$ The aflatoxin producing fungi Aspergillus flavus and Aspergillus parasiticus have been reported to grow and produce aflatoxins on many agricultural food commodities, specially under tropical climatic conditions and in the presence of moisture levels above 10 per cent. Under experimental conditions rice has been shown to be a good medium for production of aflatoxins. ${ }^{2}$

In rice, moisture levels above 10 per cent could occur due to underdrying of paddy (rough rice), especiaily during the prucessing of parvuneu rice and also due to absorption of moisture from the atmosphere at high relative humidities during storage.

The growth of fungi in market rice is a common phenomenon and the presence of aflatoxins in rice has been observed in several South-East Asian countries. ${ }^{5}$ There are reports of several incidents of human deaths suspected 
to be due to aflatoxicosis caused by the consumption of aflatoxin contaminated rice. ${ }^{3}$

Rice is the staple diet of Sri Lankans. The contamination of rice by aflatoxins even at low levels could be critical as considerable quantities of rice are consumed by the average Sri Lankan.

In view of the relevance of the rice-aflatoxin problem to human health a survey of aflatoxin contamination in rice was carried out in three locations representing the three different climatic zones in Sri Lanka during dry and wet seasons of the year, to assess the extent of contamination and relate it to possible factors which could support fungal contamination and aflatoxin accumulation. In this survey, only aflatoxin B1, which is the most toxic and most widely spread in foods, was estimated.

\section{Materials and Methods}

\subsection{Source of samples}

Samples of all available types of rice, consisting of parboiled and raw milled rice of locally grown varieties were collected from more than 90 per cent of the market places in the three towns Anuradhapura (dry zone, annual rainfall $<2000 \mathrm{~mm}$ ) Kurunegala (intermediate zone, annual rainfall $2000-2500 \mathrm{~mm}$ ) and Veyangoda (wet zone, annual rain fall $>2500 \mathrm{~mm}$ ). Samples were collected during the dry and rainy seasons of the year.

\subsection{Sampling}

When sampling was done from $1-5$ bags, each containing upto $65 \mathrm{~kg}$, several primary samples were withdrawn from three different levels in the bag using a probe grain sampler. A composite sample was prepared by pooling the three primary samples. A replicate fraction $(125 \mathrm{~g})$ from one-fourth of the composite sample was used for laboratory analysis. When the number of rice bags available for sampling was between $6-25,5$ bags were picked randomly and primary samples were withdrawn from them. When the number of bags was over 25 , they were marked into lots of 5 bags each and a sample was obtained from one bag in each lot.

Both parboiled and raw rice were sampled for analysis. The samples were packed and sealed in polythene bags for transport and storage. 


\subsection{Estimation of moisture}

The moisture content in the rice (wet weight basis) was estimated immediately on return to the laboratories (within 24 hours of collection) using a Kett PBTK moisture meter. The grain samples in sealed polythene bags were stored at $-20^{\circ} \mathrm{C}$ pending assay for aflatoxins.

\subsection{Estimation of aflatoxins}

Rice grains were ground to a fine powder in a Stein Mill Model M2. The samples in duplicate $(20 \mathrm{~g})$ were extracted by the modified $70 \%$ aqueous acetone procedure. ${ }^{4}$ The estimation of aflatoxin B1 was done on $250 \mathrm{~nm}$ silica gel G (Merck) thin layer chromatographic plates by visual comparison with standard samples of pure aflatoxin B1 (Makor, Jerusalem) in chloroform under UV light at $365 \mathrm{~nm}$. The minimum detectable level under these conditions was $12 \mu \mathrm{g} / \mathrm{kg}$ (ppb).

Solvents used in developing the chromatograms were, (a) methanol : chloroform ( $3: 97)$ equilibrated, lined tank

(b) acetone : chloroform (1:9) unequilibrated, unlined tank

\section{Results and discussion}

\subsection{Locations}

In the selection of localities for the survey, three rice producing areas were identified for sampling, as our preliminary studies indicated that it was not possible to find the area of origin of the rice, with reasonable accuracy, if sampling was done in non-rice producing areas of the country. In the three areas surveyed, all rice samples were found to be produced and processed in the same locality. In 99 per cent of the samples, the storage period as market rice was found to be less than 7 days. Occasionally, samples stored for 14-21 days were present.

\subsection{Moisture levels}

The mean moisture levels observed for all the samples was $14.9 \pm 1.4 \%$. Lowest moisture levels were observed in rice during the dry season in the intermediate zone (Kurunegala) and highest during the rainy season in the dry zone (Anuradhapura) (Table 1).

In the dry and intermediate zones, the mean moisture content in rice appeared to be higher during the rainy season than during the dry season, 
Table 1. Mean moisture content (\% wet basis) observed in rice samples from Anuradhapura, Kurunegala and Veyangoda during dry and rainy seasons

\begin{tabular}{|c|c|c|c|c|}
\hline \multirow[b]{2}{*}{$\begin{array}{l}\text { Location - } \\
\text { zone }\end{array}$} & \multicolumn{2}{|c|}{ dry } & \multicolumn{2}{|c|}{ rainy } \\
\hline & $\begin{array}{l}\text { number } \\
\text { of } \\
\text { samples }\end{array}$ & mean & $\begin{array}{c}\text { number } \\
\text { of } \\
\text { samples }\end{array}$ & mean \\
\hline $\begin{array}{l}\text { Anuradhapura } \\
- \text { dry }\end{array}$ & 101 & $14.2 \pm 1.8$ & 105 & $15.9 \pm 1.3$ \\
\hline $\begin{array}{l}\text { Kurunegala } \\
\quad \text { - intermediate }\end{array}$ & 101 & $13.8 \pm 1.1$ & 104 & $15.5 \pm 1.0$ \\
\hline $\begin{array}{c}\text { Veyangoda } \\
\text { - wet }\end{array}$ & 86 & $15.1 \pm 0.9$ & 106 & $15.1 \pm 1.2$ \\
\hline
\end{tabular}

Analysis of variance

\begin{tabular}{lrrrr}
\hline & df & ss & ms & F \\
\hline treatments & 5 & 319.8280 & & \\
location & 2 & 23.97059 & 11.985295 & $8.2640^{* * *}$ \\
season & 1 & 211.78474 & 211.78474 & $146.02822^{* * *}$ \\
$1 \times \mathrm{s}$ & 2 & 83.84651 & 41.923255 & $28.9066^{* * *}$ \\
error & 597 & 865.8280 & 1.45030 & \\
total & 602 & 1185.6600 & & \\
& & & & \\
\hline
\end{tabular}


whereas no differences in the mean moisture content was observed during the dry and rainy seasons in the wet zone.

The distribution pattern of moisture levels in rice (Table 2) showed an increase in the number of samples containing higher moisture levels during the rainy season in all three localities. The differences were marked in the dry zone.

However, the analysis of variance (Table 1) did not show any significant differences between moisture levels during dry and rainy seasons and among the three locations. On the whole the average moisture content appeared to be sufficient for slow growth of fungi in rice.

Table2.Distribution pattern of rice samples from Anuradhapura, Kurunegala and Veyangoda during dry and rainy seasons by the moisture percentage (wet basis).

\begin{tabular}{rrrrrrr}
\hline Moisture & \multicolumn{7}{c}{ area sampled } \\
\cline { 2 - 7 } & \multicolumn{1}{c}{ Percentage } & Anuradhapura & \multicolumn{2}{c}{ Kurunegala } & \multicolumn{2}{c}{ Veyangoda } \\
\cline { 2 - 7 } & dry & rainy & dry & rainy & dry & rainy \\
\hline$<11.9$ & 1 & 0 & 2 & 0 & 0 & 0 \\
$12.0-13.9$ & 43 & 14 & 52 & 3 & 8 & 15 \\
$14.0-15.9$ & 51 & 44 & 45 & 73 & 62 & 66 \\
$16.0-17.9$ & 6 & 29 & 2 & 26 & 16 & 25 \\
$>18.0$ & 0 & 18 & 0 & 2 & 0 & 0 \\
\hline Total & 101 & 105 & 101 & 104 & 86 & 106 \\
\hline
\end{tabular}

\subsection{Aflatoxin content}

Of 597 samples of rice tested for the presence of aflatoxins none of the samples contained aflatoxin B1 above the UNICEF/WHO/FAO maximum permissible level of $30 \mu \mathrm{g} / \mathrm{kg}$ (ppb) for foods for human consumption. Aflatoxin B1 was not detected in 525 samples (minimum detectable level . $12 \mu \mathrm{g} / \mathrm{kg}$ ). Of the balance there were 12 parhoiled rice samples containing $30 \mu \mathrm{g} / \mathrm{kg}$ of aflatoxin B1. Among the 60 samples which contained less than $30 \mu \mathrm{g} / \mathrm{kg}, 57$ were parboiled rice and 3 were raw rice (Table 3 ). 


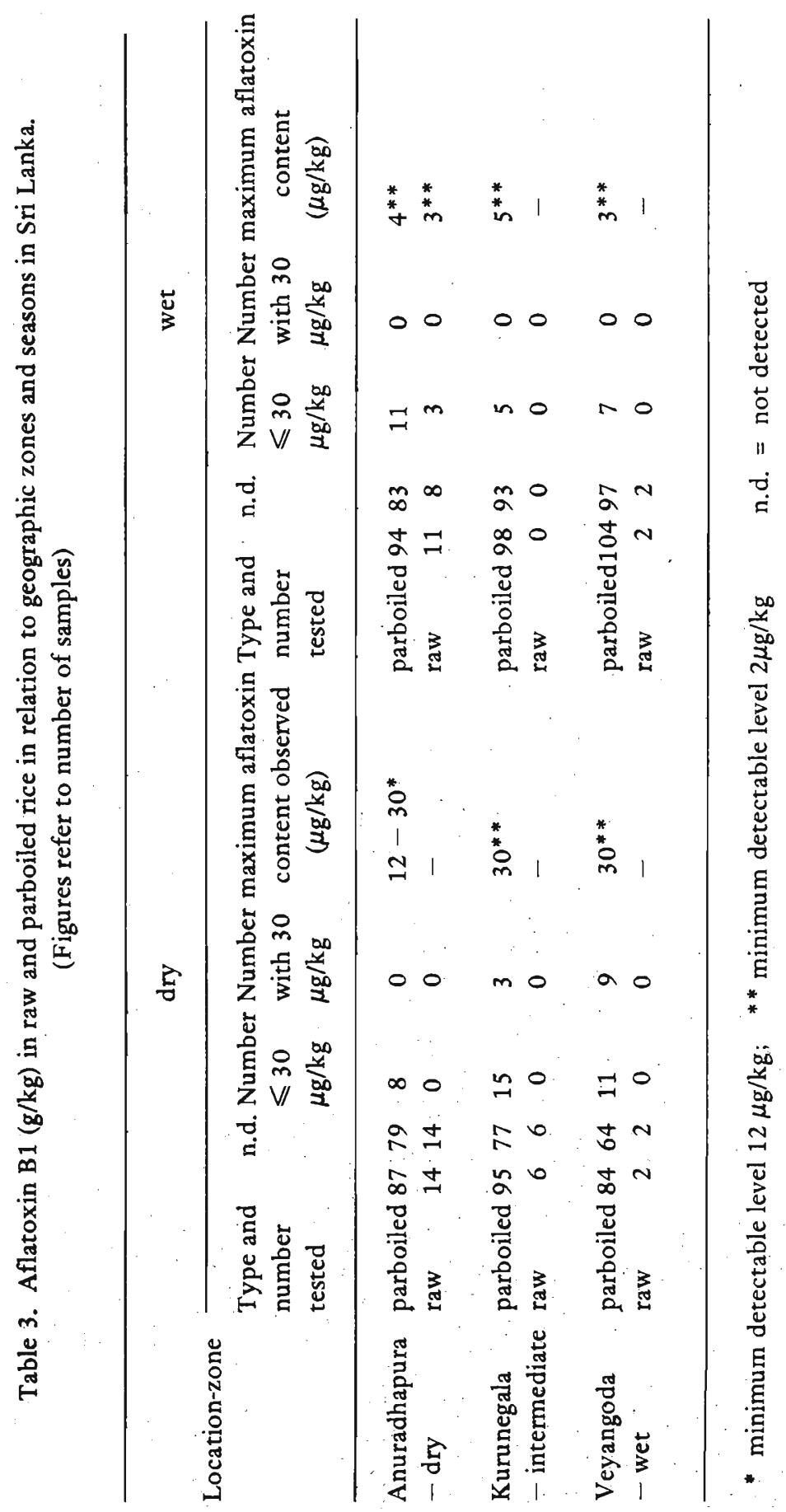


Parboiled rice is more likely to be colonized by the fungi due to high moisture levels in them caused by improper drying, after parboiling. The gelatinized starch of the parboiled rice endosperm may also be more susceptible to fungal attack than the native starch of the raw endosperm.

As regards the susceptibility of raw rice, the number of samples analysed is not sufficient for a final conclusion. It is therefore not possible to conclude whether the parboiled rice is more susceptible to aflatoxin accumulation.

The aflatoxin $\mathrm{B} 1$ levels observed in the rice samples did not show any pattern of association with the different agro-climatic zones or the seasons indicating that the observed mean moisture levels up to $16 \%$ do not influence aflatoxin accumulation in rice during storage.

Under the present conditions where rice is not stored for periods above 7 days at moisture content above $16 \%$, rice does not appear to pose a danger through aflatoxin contamination. However, the low aflatoxin levels detected in parboiled rice could indicate a potential danger specially if efficient drying is not practised after parboiling and prior to storage.

At present rice is a fast selling commodity in the market as Sri Lanka has not reached self sufficiency in rice. However, with self sufficiency in rice, which is expected in the near future, we may face problems of aflatoxin accumulation associated with longer periods of storage and at higher moisture levels as observed with prolonged storage of improperly dried rough rice. ${ }^{1}$

\section{Acknowledgements}

This work was supported by the research grant RG/82/01 of NARESA. We thank Mr. Y.H. Pemasinghe and Mr. N. Navaratna of the Department of Microbiology, University of Peradeniya for technical assistance.

\section{References}

1. CALDERWELL, D.L. (1968) Aflatoxin development and grade of undried rough rice following prolonged storage in aerated bins. Report of the Texas Agriculture Station of USDA, JRC/AE 68/XIII/8/2.

2. HESSELTINe, C.W., SHOTWELl, O.L., ELlis, J.J, STUBbLEFIELD, R.D. (1966) Bact. Rev., 30: $795-805$. 
3. LING, K.H., WANG, J.J., WU, R., TUNG, T.C., LIN, C.K., LIN, S.S. \& LIN, T.M. (1967) J. Formosan Med. Assoc. 66: 517.

4. SAMARAJEEWA, U. \& ARSECULERATNE, S.N. (1975) J. Food Sci. Tecbnol. 12: $27-31$.

5. SHANK, R.C. (1977) Adv. Mod. Toxicol. 3: 291.

6. SHANK, R.C. (1981) Environmental toxicoses in humans in Mycotoxins and N-Nitroso compounds: Environmental risks, Vol.1. CRC Press Inc., Boca Paton. Florida, p. 108. 